\title{
Efeito da nutrição da ovelha e do cordeiro sobre o perfil de ácidos graxos do músculo Triceps brachii de cordeiros $^{1}$
}

\author{
Sarita Bonagurio Gallo², Edson Ramos de Siqueira ${ }^{3}$, Gilberto Teixeira da Rosa ${ }^{4}$
}

\author{
${ }^{1}$ Projeto financiado pela Fapesp. \\ ${ }^{2}$ FAZU - Uberaba, MG. \\ ${ }^{3}$ FMVZ - UNESP - Botucatu - SP. Pesquisador do CNPq. \\ 4 In memorian.
}

\begin{abstract}
RESUMO - O experimento foi realizado com o objetivo de avaliar o efeito da suplementação da ovelha 30 dias antes do parto, da idade à desmama (45 ou 60 dias) dos cordeiros e do sistema de terminação (em confinamento - dieta total ou feno) ou a pasto sobre o perfil de ácidos graxos do músculo Triceps brachii de cordeiros machos não-castrados. O animais foram abatidos com $30 \mathrm{~kg}$ de peso corporal ou aos 150 dias de idade. Os cordeiros terminados em confinamento alimentados com feno foram abatidos pela idade e os demais pelo peso corporal. Os teores dos ácidos graxos C15:0, C16:0, C17:0, C16:1, C18:1 e C18:3 no músculo diferiram entre os sistemas de terminação dos cordeiros. O músculo dos cordeiros alimentados com dieta completa apresentou maiores valores de C16:0, C16:1 e C18:1, enquanto o músculo daqueles alimentados com feno e em pastagem apresentou maiores teores de C18:3. A dieta alterou o perfil de ácidos graxos no músculo dos cordeiros. A suplementação das ovelhas 30 dias antes do parto e a idade a desmama não afetaram o perfil de ácidos graxos.
\end{abstract}

Palavras-chave: confinamento, desmama, ovinos, pastagem, suplementação

\section{Effect the sheep and lamb nutrition on the of Triceps brachii muscle fatty acid profile of the lambs}

\begin{abstract}
The objective of this work was to evaluate the supplementation of ewes 30 days before lambing, of the weaning age (45 or 60 days) of lambs and of the finishing system (on confinement - full diet or hay) or in grass on the profile of Tríceps brachii muscle fatty acid of no castrated male lambs. The animals were slaughter with $30 \mathrm{~kg}$ body weight or at 150 days-old. The lambs finished on confinement fed were slaughtered by age and the others by body weight. The content of fatty acids C15:0, C16:0, C17:0, C16:1, C18:1 and C18:3 were different among the lambs finishing systems. The muscle of lambs fed full diet shown highest values of C16:0, C16:1 and C18:1, while the muscle those fed hay or grass shown highest values of C18:3. The diet affected the fatty acid profile of muscle of lambs. The ewes supplementation 30 days before lambing and the weaning age did not affect the fatty acid profile.
\end{abstract}

Key Words: confinement, weaning, ovine, grass, supplementation

\section{Introdução}

Os lipídios realizam muitas funções no corpo, por exemplo, algumas vitaminas lipossolúveis têm funções reguladoras ou de coenzimas e as prostaglandinas e hormônios esteróides desempenham importantes papéis no controle da homeostase do corpo. Durante muito tempo, a gordura foi considerada fonte de energia na alimentação humana, mas depois de 1960, a gordura saturada foi associada a doenças coronárias e algumas formas de câncer. Assim, iniciaram-se estudos para a seleção, manejo e alimentação de animais visando reduzir a quantidade de gordura da carcaça. No entanto, com a aplicação dessas estratégias, houve prejuízo na palatabilidade da carne. Atualmente, tem-se conhecimento de que, além dos ácidos graxos essenciais, alguns são benéficos para a saúde, como o ácido linoléico conjugado, conhecido também por CLA, que tem ação anticarcinogênica e antiarterogênica, induzem a diminuição da gordura corporal e o aumento do conteúdo protéico. Há também os ácidos graxos poliinsaturados de cadeia longa n-3, principalmente os eicosapentanóico e docasahexanóico, que previnem doenças coronárias (Cassens, 1999).

A composição de ácidos graxos na carne difere entre cordeiros lactantes e desmamados (Bas \& Morand-Fehr, 2000). A composição da gordura da carne de cordeiros amamentados é a mesma do leite materno, mas pode ser modificada pelo consumo de alimento complementar (Velasco et al., 2004). Em estudo realizado por Bas \& Morand-Fehr (2000), 
os cordeiros terminados a pasto depois da desmama tiveram maior porcentagem de C18:3 (ácido linolênico). As dietas mais ricas em energia metabolizável apresentaram aumento da porcentagem de C16:0 (palmítico), C16:1 (palmitoleíco), C15:0 (pentadecanóico) e C17:0 (heptadecanoíco) e decréscimo de C18:0 (esteárico), C18:1 (oléico) e C18:2 (linoléico). Dietas mais protéicas foram pobres em C16:0 e C18:0 e ricas em C16:1, C18:1 e C18:3. Dietas ricas em fibra tiveram maior porcentagem de C18:0 e menor de C18:2. Dietas ricas em gordura foram pobres em C16:1, C18:3 e C17:0. Ressalta-se que a matéria-prima utilizada na composição da dieta altera a composição de ácidos graxos, mesmo que sejam isoprotéicas e isoenergéticas (Bas \& Morand-Fehr, 2000).

A porcentagem de ácidos graxos poliinsaturados é maior na gordura subcutânea de cordeiros terminados em confinamento, em razão da grande quantidade de concentrado ingerido, que modifica as reações bioquímicas do rúmen. Nessas alterações, alguns ácidos graxos poliinsaturados podem escapar do processo de hidrogenação e fazer parte dos lipídios estruturais dos microrganismos ruminais. Gorduras subcutânea e intramuscular de cordeiros em pastagem apresentam adequada proporção de n-6/n-3 de ácidos graxos poliinsaturados em comparação a essas mesmas gorduras de cordeiros no confinamento. Essa diferença é reflexo da composição de ácidos graxos da dieta. Forragem contém alto nível de ácidos graxos linolênico (C18:3), precursor da série n-3 de ácidos graxos. O concentrado, ao contrário, tem alto teor de ácido linoléico (C18:2), precursor da série n-6 (Díaz et al., 2002).

O objetivo neste estudo foi avaliar as conseqüências da suplementação alimentar da ovelha 30 dias antes do parto, a idade à desmama de cordeiros (45 ou 60 dias de idade) e o sistema de terminação de cordeiros machos nãocastrados, confinados (dieta completa ou feno) ou a pasto, sobre a composição de ácidos graxos.

\section{Material e Métodos}

O experimento foi realizado na fazenda Palmeira da Serra, no município de Pratânia, SP. O confinamento dos cordeiros foi feito no Setor de Ovinocultura da Faculdade de Medicina Veterinária e Zootecnia, UNESP, Botucatu - SP.

Realizou-se a cobertura de 53 fêmeas mestiças Ile de France $\times$ Bergamácia, com 2 a 6 anos de idade (nenhuma primípara), acasaladas com macho da raça Ile de France. No entanto, após o parto, foram usadas apenas as fêmeas que pariram machos (parto simples).

Todas as matrizes foram mantidas em pastagens de Panicum maximum cv. Tanzânia, em sistema de pastejo rotacionado, até 30 dias antes do parto, quando foram separadas em dois grupos. O primeiro grupo foi suplementado com dieta composta de concentrado e feno, balanceada segundo as exigências do NRC (1985), equivalente a 1,5\% do peso corporal; e o segundo grupo não recebeu suplementação. A data provável de parição foi obtida por meio do controle de monta da propriedade.

Após o parto, todas as ovelhas foram suplementadas de forma idêntica, mas foram subdivididas pela idade de desmama dos cordeiros, que correspondia em 45 ou 60 dias de idade. Depois da desmama, os cordeiros foram distribuídos aleatoriamente em três sistemas de terminação. O primeiro sistema consistiu da terminação de cordeiros em regime de confinamento total, com uma dieta completa, segundo as exigências do NRC (1985). No segundo, os cordeiros também foram terminados em confinamento total e receberam somente feno à vontade. No terceiro sistema os animais permaneceram no pasto. O peso de abate estabelecido foi de $30 \mathrm{~kg}$ ou 150 dias de idade.

$\mathrm{O}$ alimento era oferecido, a vontade, aos animais uma vez ao dia em quantidade calculada para que houvesse sobra de $20 \%$. A dieta completa fornecida aos cordeiros confinados, em baias coletivas, era composta por uma ração comercial e feno de Aruana, nas proporções de 30\% de concentrado e $70 \%$ de volumoso, para ganho de peso de 300 g/dia conforme a recomendação do NRC (1985). Os cordeiros foram confinados em baias coletivas e alimentados só com feno inteiro de Aruana.

Os cordeiros do sitema a pasto foram mantidos em pastagens de Panicum maximum cv. Tanzânia, em sistema de pastejo rotacionado, com acesso a água e sal mineral à vontade, e receberam um adicional de $200 \mathrm{~g}$ da ração comercial por dia, conforme o manejo utilizado na Fazenda Palmeira da Serra, sem atingir as recomendações do NRC (1985). O tratamento dos cordeiros terminados a pasto foi imposto no intuito de averiguar o manejo aplicado pelo produtor rural. O pasto mantinha carga animal de dez cordeiros por hectare e assim que a quantidade de forragem oferecida diminuía os animais eram transferidos para outro piquete.

O valor nutricional da pastagem (Tabela 1) variou com o tempo do experimento;o que consta na Tabela 1 é uma média dos valores obtidos ao longo do período experimental. O valor da ração expresso na tabela está de acordo com os dados fornecidos pelo fabricante e os valores do feno e do pasto foram obtidos pela análise bromatológica feita segundo procedimentos adotados no Laboratório de Nutrição do Departamento de Melhoramento e Nutrição Animal da FMVZ - UNESP - Botucatu.

Ao atingirem o peso de $30 \mathrm{~kg}$ ou 150 dias de idade, os cordeiros machos não-castrados foram abatidos após jejum 
Tabela 1 - Composição química (\%MS) do concentrado comercial, do feno e da pastagem

Table 1 - Chemical composition (\%DM) of the commercial concentrate, hay, pasture

\begin{tabular}{lcrr}
\hline & $\begin{array}{c}\text { Concentrado comercial } \\
\text { Commercial concentrate }\end{array}$ & $\begin{array}{c}\text { Feno } \\
\text { Hay }\end{array}$ & $\begin{array}{c}\text { Pasto } \\
\text { Pasture }\end{array}$ \\
\hline MS (DM) & 87 & 88,67 & 90,20 \\
PB (CP) & 18 & 11,42 & 5,29 \\
EE & 1,5 & 1,40 & 1,69 \\
Mineral & 10 & 9,77 & 8,48 \\
FDN (NDF) & & 75,24 & 74,34 \\
FDA (NDA) & 2 & 55,62 & 50,60 \\
Ca & 0,4 & & \\
P & & & \\
\hline
\end{tabular}

sólidos de 16 horas. As carcaças foram refrigeradas em câmara fria por 24 horas, em temperatura de $7 \pm 2^{\circ} \mathrm{C}$. Após este período, as carcaças foram seccionadas longitudinalmente em duas meias-carcaças para realização dos cortes comerciais no lado esquerdo, nas seguintes partes: paleta, lombo, costeleta, pernil, peito e fralda. Na paleta, o músculo Triceps brachii foi retirado para análise do teor de ácidos graxos.

Amostras em duplicata foram utilizadas para determinação do teor de ácidos graxos na carne de dois cordeiros por tratamento. A extração dos lipídios foi feita segundo metodologia de Bligh \& Dyer (1959). Amostras (10 g) foram trituradas, colocadas em erlemeyer com $10 \mathrm{~mL}$ de clorofórmio e $20 \mathrm{~mL}$ de metanol, agitadas por 5 minutos e acrescidas de $10 \mathrm{~mL}$ de metanol e novamente agitados por 5 minutos. A solução foi passada em funil de separação. A parte superior da solução foi composta de metanol, água e extratos não-lipídicos e foi descartada, enquanto a parte inferior foi composta de clorofórmio e lipídios e colocada em outro balão. A esterificação foi feita adicionando-se $5 \mathrm{~mL}$ de solução metanólica à solução de clorofórmio e lipídio deixando-a em refluxo por 5 minutos. Adicionou-se um reagente de esterificação $(15 \mathrm{~mL})$ e novamente colocou-se a solução metanólica no refluxo por 5 minutos. Depois, a solução foi passada pelo funil de separação com $25 \mathrm{~mL}$ de éter de petróleo e $50 \mathrm{~mL}$ deágua destilada e a fase aquosa (fase inferior) foi descartada. A fase etérea foi lavada com $25 \mathrm{~mL}$ de água destilada por duas vezes e o solvente foi evaporado em fluxo de nitrogênio líquido.

O perfil de ácidos graxos foi determinado por cromatografia gasosa de alta resolução utilizando-se um cromatógrafo a gás (HO 5890) equipado com coluna capilar DB $-23(60 \mathrm{~m} \times 0,25 \mathrm{~mm} \times 0,25 \mu \mathrm{m})$ acoplado a um detector de ionização de chama. A programação de temperatura foi $130^{\circ} \mathrm{C}(1 \mathrm{~min})$ a $170^{\circ} \mathrm{C}\left(6,5^{\circ} / \mathrm{min}\right), 170^{\circ} \mathrm{Ca} 215^{\circ} \mathrm{C}\left(2,75^{\circ} \mathrm{C} / \mathrm{min}\right)$, $215^{\circ} \mathrm{C}$ ( $\left.12 \mathrm{~min}\right), 215^{\circ} \mathrm{C}$ a $230^{\circ} \mathrm{C}$ ( $\left.40^{\circ} / \mathrm{min}\right)$ e $230^{\circ} \mathrm{C}$ ( $\left.3 \mathrm{~min}\right)$. As temperaturas do injetor e detector foram de $270^{\circ} \mathrm{C}$ e $280^{\circ} \mathrm{C}$, respectivamente. As amostras $(0,2 \mu \mathrm{L})$ foram injetadas pela técnica de injeção direta. A análise de perfil dos ácidos graxos foi realizada no Laboratório de Óleos e Gorduras do Departamento de Agroindústria, Alimentos e Nutrição da ESALQ/USP, Piracicaba - SP.

Odelineamento foi inteiramente casualizado, em esquema fatorial $2 \times 2 \times 3$, com dois níveis nutricionais da ovelha antes do parto, duas idades à desmama (45 e 60 dias) e três sistemas de terminação (confinamento com dieta completa ou feno, e em pastagem). Todos os dados foram analisados pelo procedimento GLM do SAS (SAS, 1989). Adotou-se significância de $5 \%$, pelo teste de comparação $t$, utilizando-se duas repetições por animal e número diferente de animais por tratamento, de 3 a 5 .

\section{Resultados e Discussão}

As variáveis analisadas foram a suplementação das ovelhas antes do parto, a idade à desmama e o sistema de terminação do cordeiro (confinamento com dieta completa; confinamento somente com feno; e em pastagem).

Os principais ácidos graxos presentes na gordura intramuscular do músculo Triceps brachii de cordeiros, em ordem decrescente, foram: ácido oléico (C18:1), palmítico (C16:0) e esteárico (C18:0; Tabela 2), assim como descrito por Velasco et al. (2004). Os teores dos ácidos graxos C10:0, C13:0 C20:0, C22:0, C18:1 trans, C14:1trans, C20:1 cis e C22:1 cis foram menores que $0,03 \%$, valor considerado muito pequeno. Por isso, não constam na discussão do trabalho.

As concentrações dos ácidos graxos saturados C15:0, C16:0 e C17:0, dos monoinsaturados C16:1 e C18:1 e poliinsaturados C18:3 foram influenciadas pelo sistema de terminação, no entanto, não foram afetadas pelos demais efeitos testados. Em virtude dessa diferença na porcentagem de ácidos graxos saturados e insaturados, a relação entre insaturados:saturados também foi diferente (Tabela 2).

Para o ácido graxo pentadecanóico (C15:0; P = 0,0001), os cordeiros alimentados somente com feno apresentaram valores maiores e foram seguidos pelos cordeiros da pastagem e pelos alimentados com dieta completa. Esses resultados diferem dos descritos por Bas \& Morand-Fehr (2000), que encontraram maior teor de C15:0 para dietas com alto teor de energia metabolizável. O valor encontrado neste estudo (0,97\%) foi semelhante ao obtido por Velasco et al. (2004), que registraram valor de 0,95\% para C15:0 na carne dos cordeiros desmamados mantidos em pastagem e alimentados com cevada. Rowe et al. (1999) e Díaz et al. (2002) compararam cordeiros terminados em confinamento ou em pastagem e não encontraram diferença na concentração dos ácidos graxos C15:0 nos cordeiros dos diferentes sistemas de terminação. Outra possível explicação para a 
diferença na porcentagem de C15:0 entre os animais pode estar relacionada ao peso corporal de abate, apesar de o peso de fazenda não ter sido significativo como covariável dos dados. Apesar da pequena diferença de peso corporal ao abate (2 kg), no estudo de Velasco et al. (2000), cordeiros mais leves (como aqueles alimentados com feno) tiveram maior porcentagem de C15:0.

A carne dos cordeiros confinados com dieta completa apresentou os maiores valores $(\mathrm{P}=0,0225)$ de ácido graxo saturado palmítico (C16:0), que é muito importante por ser encontrado em grande quantidade na gordura da carne e estar correlacionado positivamente ao aumento do colesterol sanguíneo (Banskalieva et al., 2000). A carne dos cordeiros alimentados com a dieta completa apresentou os maiores teores de C16:0 em comparação à dos cordeiros que receberam somente concentrado. Provavelmente, a associação da fibra e da energia da dieta eleva a porcentagem deste ácido graxo (Bas \& Morand-Fehr, 2000). O local e o tipo de forrageira consumida pelos cordeiros do sistema de confinamento a pasto podem ter alterado a composição dos ácidos graxos, inclusive de C16:0 (Fisher et al., 2000). A dieta, portanto, pode alterar o perfil dos ácidos graxos. Dietas com óleo de peixe na alimentação de cordeiros pode aumentar a porcentagem de C16:0 na gordura intramuscular do músculo Longissimus dorsi (Cooper et al., 2004). Para a gordura subcutânea da região lombar, a carne dos cordeiros terminados em pastagem apresentou valores menores de C16:0 em comparação à daqueles terminados em confinamento, enquanto, para a gordura do pernil, não houve diferença entre os sistemas de terminação (Bas \& Morand-Fehr, 2000). Em outros trabalhos, a terminação em confinamento ou em pastagem (Rowe et al., 1999) e a dieta fornecida (Ponnampalam et al., 2001; Velasco et al., 2004), não alteraram a porcentagem do ácido palmítico.

Os teores do ácido graxo heptadecanoíco (C17:0) foram maiores $(\mathrm{P}=0,0024)$ na carne dos cordeiros alimentados com feno. Segundo Bas \& Morand-Fehr (2000), dietas com alto teor de EE têm menor porcentagem de C17:0. Portanto, a dieta somente de feno pode ter alterado a porcentagem de C17:0 por ter baixo teor de EE. Em trabalhos realizados por Rowe et al. (1999) e Díaz et al. (2002), a carne dos cordeiros terminados em confinamento apresentou maior teor de C17:0 em comparação à daqueles terminados a pasto. O confinamento nesses estudos pressupõe uma dieta rica em energia. Nesta pesquisa, os cordeiros confinados e alimentados somente com feno, apesar de não terem sido mantidos em pastagem, foram alimentados com dieta com baixo teor de EE. Novamente, pode-se inferir que o nível nutricional da dieta afetou a porcentagem de C17:0 na gordura intramuscular da carcaça.

As concentrações dos ácidos graxos monoinsaturados C16:1 (palmitoleíco) e C18:1 (oléico) diferiram entre os sistemas de terminação e foram maiores $(\mathrm{P}<0,005)$ nos cordeiros terminados em confinamento alimentados com dieta completa. A porcentagem do ácido graxo C18:3 foi maior nos cordeiros alimentados com feno, seguidos dos cordeiros do sistema de terminação a pasto e daqueles alimentados com dieta completa (Tabela 2 ).

Os ácidos graxos mono e poliinsaturados são considerados bons para a saúde humana. Cooper et al. (2004) observaram que a dieta pode alterar a porcentagem de C16:1 e C18:1. Nos trabalhos de Fisher et al. (2000) e Velasco et al. (2004), a porcentagem de C18:1 foi maior nas dietas com

Tabela 2 - Perfil de ácidos graxos do músculo Triceps brachii de cordeiros terminados em confinamento (dieta completa ou feno) ou em pastagem

Table 2 - $\quad$ Profile of fatty acids from the muscle Triceps Brachii from lambs finished in confinement (complete diet or hay) or in pasture

\begin{tabular}{|c|c|c|c|c|c|c|}
\hline \multirow[b]{2}{*}{ AG } & \multicolumn{6}{|c|}{$\begin{array}{l}\text { Sistema de terminação } \\
\text { Finishing system }\end{array}$} \\
\hline & $\begin{array}{l}\text { Dieta completa } \\
\text { Complete diet }\end{array}$ & EP & $\begin{array}{l}\text { Feno } \\
\text { Hay }\end{array}$ & EP & $\begin{array}{l}\text { Pastagem } \\
\text { Pasture }\end{array}$ & EP \\
\hline C12:0 & 1,18 & 0,13 & 1,65 & 0,16 & 1,53 & 0,12 \\
\hline C14:0 & 7,15 & 0,53 & 8,91 & 0,59 & 8,14 & 0,48 \\
\hline C15:0 & $0,71 \mathrm{a}$ & 0,05 & $1,36 \mathrm{c}$ & 0,05 & $0,97 b$ & 0,04 \\
\hline C18:0 & 14,03 & 0,94 & 15,85 & 1,05 & 16,70 & 0,86 \\
\hline C16:1 & $2,30 \mathrm{~b}$ & 0,12 & 1,83a & 0,13 & $1,86 a$ & 0,11 \\
\hline C18:1 & $38,01 b$ & 0,98 & $34,23 a$ & 1,09 & $34,83 a$ & 0,89 \\
\hline C18:2 & 5,59 & 0,50 & 4,44 & 0,56 & 5,36 & 0,46 \\
\hline C18:3 & $0,51 b$ & 0,18 & $1,42 \mathrm{a}$ & 0,20 & $0,88 a b$ & 0,15 \\
\hline Saturado Saturate & $53,62 \mathrm{a}$ & 0,81 & $58,02 b$ & 0,91 & $57,04 b$ & 0,74 \\
\hline
\end{tabular}

Médias com letras distintas na linha diferem $(P<0,05)$ pelo teste $t$.

Means with different letters within a row differ $(P<0.05)$ by test $t$. 
cereais em comparação à pastagem. Os resultados obtidos nesta pesquisa foram similares aos relatados por Rowe et al. (1999), que constataram valores maiores para os dois ácidos graxos em cordeiros terminados em confinamento em relação aos mantidos em pastagem (Tabela 2). Provavelmente, o aumento no teor desses ácidos graxos está relacionado aos altos teores de energia e proteína da dieta fornecida.

O ácido graxo linolênico (C18:3) é essencial para a saúde humana. No entanto, apresenta menor ponto de fusão e maior risco de peroxidação da gordura com a formação de "flavour" mais intenso (Cifune et al., 2000). No entanto, o efeito negativo da peroxidação só ocorre na presença de grande quantidade deste ácido graxo. A dieta pode alterar a concentração de C18:3 (Cooper et al., 2004). A forragem contém alto teor de C18:3 (Díaz et al., 2002) e, por isso, os cordeiros alimentados com feno e mantidos em pastagem apresentaram maiores valores. O feno constitui fonte de alimento na época da seca e pode ser empregado como volumoso em confinamentos; seus nutrientes estão mais concentrados em relação à pastagem, uma vez que esse alimento contém menor teor de água. Esse pode ser o motivo pelo qual os cordeiros alimentados somente com feno apresentaram maior teor de C18:3. O maior valor de C18:3 para os cordeiros mantidos em pastagem também foi observado por Russo et al. (1999), Fisher et al. (2000) e Díaz et al. (2002). Díaz et al. (2002) afirmaram que os animais criados a pasto produzem carne mais saudável à saúde humana se comparados a cordeiros criados em confinamento, em razão da melhor relação de (n-6)/(n-3), entre outros fatores.

O teor de ácidos graxos saturados foi maior na carne dos cordeiros com alimentação à base de forragem e menor teor de insaturados. Conseqüentemente, houve diferença na relação de insaturados:saturados (Tabela 2). Essas relações são descritas de várias formas na literatura. Alguns autores consideram a proporção de poliinsaturados:saturados (Rowe et al., 1999) ou somente os ácidos graxos C18:2, C18:3, C16:0 e C18:0 (Velasco et al., 2000). De qualquer modo, esta relação indica que a porcentagem de ácidos graxos saturados na carne de cordeiros é maior que a dos ácidos graxos insaturados e que o sistema de alimentação na terminação pode influenciar na composição de ácidos graxos.

\section{Conclusões}

A suplementação da ovelha antes do parto e a idade à desmama não influenciaram o perfil de ácidos graxos na carne de cordeiros abatidos com $30 \mathrm{~kg}$ de peso vivo ou aos 150 dias de idade. O tipo de alimento fornecido aos cordeiros durante a terminação influencia o perfil de ácidos graxos. Os cordeiros alimentados com dieta com maior quantidade de fibra tiveram maior quantidade de C18:3 na gordura intramuscular. A carne dos cordeiros terminados em confinamento com dieta completa apresentou menor teor de ácidos graxos saturados.

\section{Literatura Citada}

BANSKALIEVA, V.; SAHLU, T.; GOETSCH, A.L. Fatty acid composition of goat muscle and fat depots: a review. Small Ruminant Research, v.37, p.255-268, 2000.

BAS, P.; MORAND-FEHR, P. Effect of nutritional factors on fatty acid composition of lamb fat deposits. Livestock Production Science, v.64, p.61-79, 2000.

BLIGH, E.G.; DYER, W.J. A rapid method of total lipid extraction and purification. Canadian Journal Biochemistry Physiology, v.37, p.911-917, 1959.

CASSENS, R.G. Contribution of meat to human health. In: INTERNATIONAL CONGRESS OF MEAT SCIENCE AND TECHNOLOGY, 45., 1999, Yokohama. Anais... Yokohama: 1999. p.642-647.

CIFUNE, G.F.; NAPOLITANO, F.; PACELLI, C. et al. Effect of age at slaughter on carcass traits, fatty acid composition and lipid oxidation of Apulian lambs. Small Ruminant Research, v.35, p.65-70, 2000.

COOPER, S.L.; SINCLAIR, L.A.; WILKINSON, R.G. et al. Manipulation of the $n-3$ polyunsaturated fatty acid content of muscle and adipose tissue in lambs. Journal of Animal Science, v.82, p.1461-1470, 2004.

DÍAZ, M.T.; VELASCO, S.; CAÑEQUE, V. et al. Use of concentrate or pasture for fattening lambs and its effect on carcass and meat quality. Small Ruminant Research, v.43, p.257-268, 2002.

FISHER, A.V.; ENSER, M.; RICHARDSON, R.L. et al. Fatty acid composition and eating quality of lamb types derived from four diverse breed x production systems. Meat Science, v.55, p.141147,2000 .

NATIONAL RESEARCH COUNCIL - NRC. Nutrient requirements of domestic animals: nutrient requeriments of sheep. Washington, D.C.: National Academy Press, 1985. 99p.

PONNAMPALAM, E.N.; SINCLAIR, A.J.; EGAN, A.R. et al. Effect of diets containing n-3 fatty acids on muscle long chain n-3 fatty acid content in lambs fed low- and medium- quality roughage diets. Journal of Animal Science, v.79, p.698-706, 2001.

ROWE, A.; MACEDO, F.A.F.; VISENTAINER, J.V. et al. Muscle composition and fatty acid profile in lambs fattened in drylot or pasture. Meat Science, v.51, p.283-288, 1999.

RUSSO, C.; PREZIUSO, G.; CASAROSA, L. et al. Effect of diet energy source on the chemical - physical characteristics of meat and depot fat of lambs carcasses. Small Ruminant Research, v.33, p.77-85, 1999.

STATISTICAL ANALYSIS SYSTEM - SAS. Procedures guide. Release 6. 3ed. Cary, 1989. 1686p.

VELASCO, S.; CAÑEQUE, V.; LAUZURICA, S. et al. Effect of different feeds on meat quality and fatty acid composition of lambs fattened at pasture. Meat Science, v.66, p.457-465, 2004.

VELASCO, S.; LAUZURICA, S.; CAÑEQUE, V. et al. Carcass and meat quality of Talaverana breed sucking lambs in relation to gender and slaughter weight. Animal Science, v.70, n.2, p.253263, 2000 . 